\title{
Topographic signature of debris flow dominated channels: implications for hazard assessment
}

\author{
R. Santos \& R. Menéndez Duarte \\ Indurot, University of Oviedo, Spain
}

\begin{abstract}
Debris flows constitute an important transport mechanism in mountain headwaters, which results in a topographic signature that is significantly different from that of fluvial valleys. This signature is readily visible in drainage area-slope diagrams, where fluvial reaches follow a power law distribution described by the equation $S=K A^{-n}$, where $S$ is channel slope, $A$ drainage area and $K$ and $n$ are constants. On the other hand, headwater channels with evidences of debris-flow activity clearly depart from this trend. This paper provides additional evidences for this phenomenon with data from a headwater basin on the northern slope of the Cantabrian Cordillera (Spain), where channels with evidences of debris-flow activity significantly depart from the power law function defined by reaches where fluvial processes are dominant; the transition between these two domains is analogous to those described in other humid, mountainous regions. Identification of dominant processes in headwater channels is based on field recognition of debris flow evidences. This paper also explores the implications of this topographic signature for the analysis of debris flow hazard at a regional scale. A significant percentage of the drainage network in the study area is characterized by the morphometric attributes of debris flow dominated channels. As a result, numerous infrastructures are potentially affected by this process, mainly roads and buildings. Additionally, the analysis suggests that some settlements may also be threatened by debris flows. This work shows that a morphometric analysis based on the drainage area-slope relation may be a useful criterion for a preliminary identification of channels where debris flows are likely to occur.
\end{abstract}

Keywords: debris flow, hazard, morphometry, headwater channels, GIS. 


\section{Introduction}

Debris flows pose a serious hazard to human lives and infrastructures in mountain regions throughout the world, where they constitute the main threat to human settlements (Hewitt [1]). The first step in debris flow hazard analysis is the recognition of potentially hazardous sites, which is usually achieved combining several techniques, including geomorphic observations (e.g. levees, oversized boulders, matrix-supported facies), interpretation of remote sensing images and analysis of historical events (Jakob [2]).

Topographic factors exert a major control on debris flow occurrence, and therefore identification of debris flow prone areas usually incorporates topographic thresholds that define the range of conditions within which debris flows are likely to occur. For instances, VanDine [3] noted that debris flow prone channels in the Canadian Cordillera are characterized by relatively small drainage basins $\left(0.4\right.$ to $\left.7.0 \mathrm{~km}^{2}\right)$ and gradients usually greater than $10^{\circ}$. However, it is widely recognized that morphometric characteristics of debris flow prone channels can be very variable, depending mainly on sediment composition, particle size, water content and volume of mobilized debris. Topographic information has also been employed as a criterion for the identification of debris flow prone fans, as opposed to fans where fluvial processes prevail. Recent work in mountain regions suggests that morphometric differences between debris flow and fluvially dominated fans are consistent at regional scales, implying that they may be a valid criterion for hazard identification (e.g. de Scally and Owens [4]; Crosta and Frattini [5]; Wilford et al. [6]).

The topographic signature of debris flow dominated channels has also been recently explored in the context of the stream-power river incision model, which states that, under steady state conditions, channel slope can be expressed as a power function of contributing area (e.g. Whipple and Tucker [7]):

$$
S=K A^{-n}
$$

where $S$ is channel slope, $A$ is contributing area and $K$ and $n$ are empirical coefficients. This model is often represented in a logarithmic area-slope diagram, where data follow a linear distribution. However, relatively steep channels depart from this trend, as has been shown in different regions. This observation was first interpreted by Seidl and Dietrich [13] in the Oregon Coast Range as a topographic signature of debris flow dominated channels. Montgomery and Foufoula-Georgiou [15] found the same pattern in drainage basins of the Western United States and also concluded that the inflection in the drainage areaslope relation reflects a morphometric threshold between fluvially and debris flow dominated channels, (fig. 1). Further research in different mountain regions reported similar trends in drainage area-slope plots (e.g. Ijjasz-Vasquez and Bras [8]), and provided field evidence of the dominance of debris flows in headwater channels (e.g. Stock and Dietrich [9]; Stock et al. [10]; Brardinoni and Hassan [11]). Accordingly, area-slope diagrams have been extensively used to define the morphometric extent of process domains, which are defined as regions where 
sediment transfer is controlled by one dominant geomorphic process (e.g. Montgomery and Foufoula-Georgiou [15]; Stock and Dietrich [9]; Brardinoni and Hassan [11]).

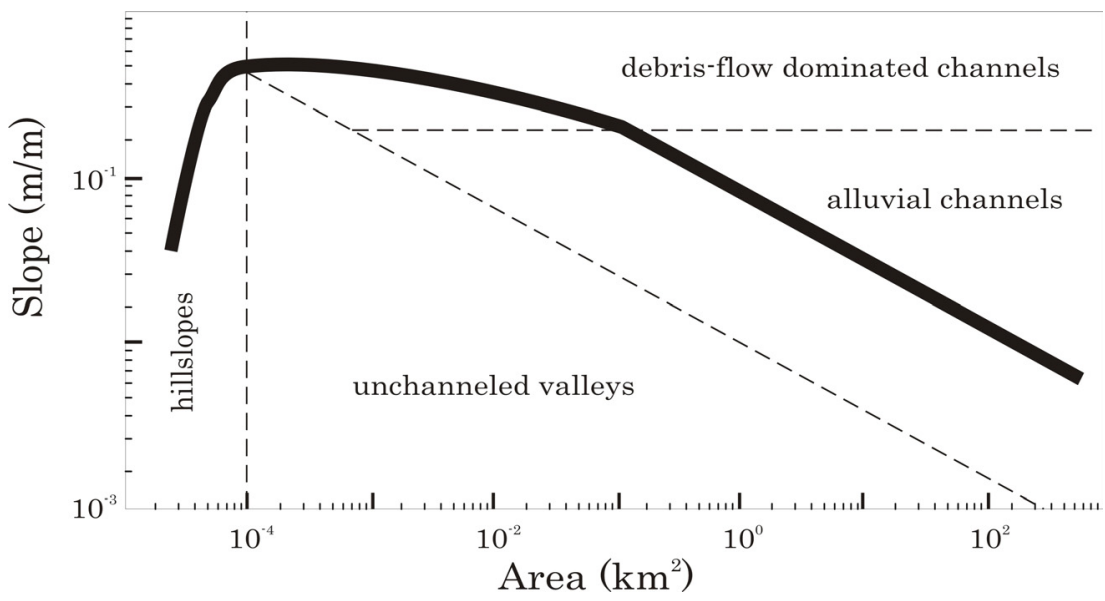

Figure 1: Extent of process domains in a logarithmic area-slope diagram (after Montgomery and Foufoula-Georgiou [15]).

\section{Study area}

This study presents additional topographic and field evidences of the topographic signature of debris flow dominated channels (henceforth referred to as colluvial channels, as opposed to fluvial or alluvial channels, according to Montgomery and Buffington [12]), with data from the Cantabrian Cordillera, Spain. It also explores the potential application of this topographic signature as a criterion for the recognition of debris flow prone channels at a regional scale and examines its use for hazard analysis.

The study area is located on the northern slope of the Cantabrian Cordillera, a mountain range running parallel to the Gulf of Biscay coast, (fig. 2). Bedrock is a relatively homogeneous, Cambrian-Ordovician sequence composed mainly of quartzite, with intercalations of sandstone and slate. The geological structure is the result of the Variscan Ogoreny, and is dominated by relatively high dip angles $\left(32-88^{\circ}\right)$ and a prevailing NE-SW strike.

From a climatic point of view, the study area is characterized by moderate temperatures and relatively abundant rainfall, with monthly precipitation ranging from 100 to $140 \mathrm{~mm}$. The modern landscape results from the combination of fluvial incision and gravity-driven slope processes, although some valley heads still preserve glacial forms related to the Würm glaciation, in the southern margin of the study area. The relief is relatively steep, with an average slope of $31^{\circ}$ and elevations ranging from 560 to more than $1500 \mathrm{~m}$. Bedrock lithology and structure exert an important control on the development of the drainage network, since it determines the orientation of high-order valleys and principal ridges. 
Colluvial deposits are abundant throughout the study area, resulting in channels being incised on loose and relatively coarse sediment.

Debris flows constitute a common transport mechanism in headwater channels of the Cantabrian Cordillera, although little is known about their geomorphic significance in terms of frequency, magnitude and denudation rates. The record of historical debris flows in the Cantabrian Cordillera is limited, and refers almost exclusively to events that caused significant damage to roads and settlements. Interestingly, these destructive events have not always taken place on debris fans, but also along relatively gentle reaches of headwater channels. Systematic identification of these reaches is usually more difficult than that of debris flow prone fans, as they have no distinctive topographic features.

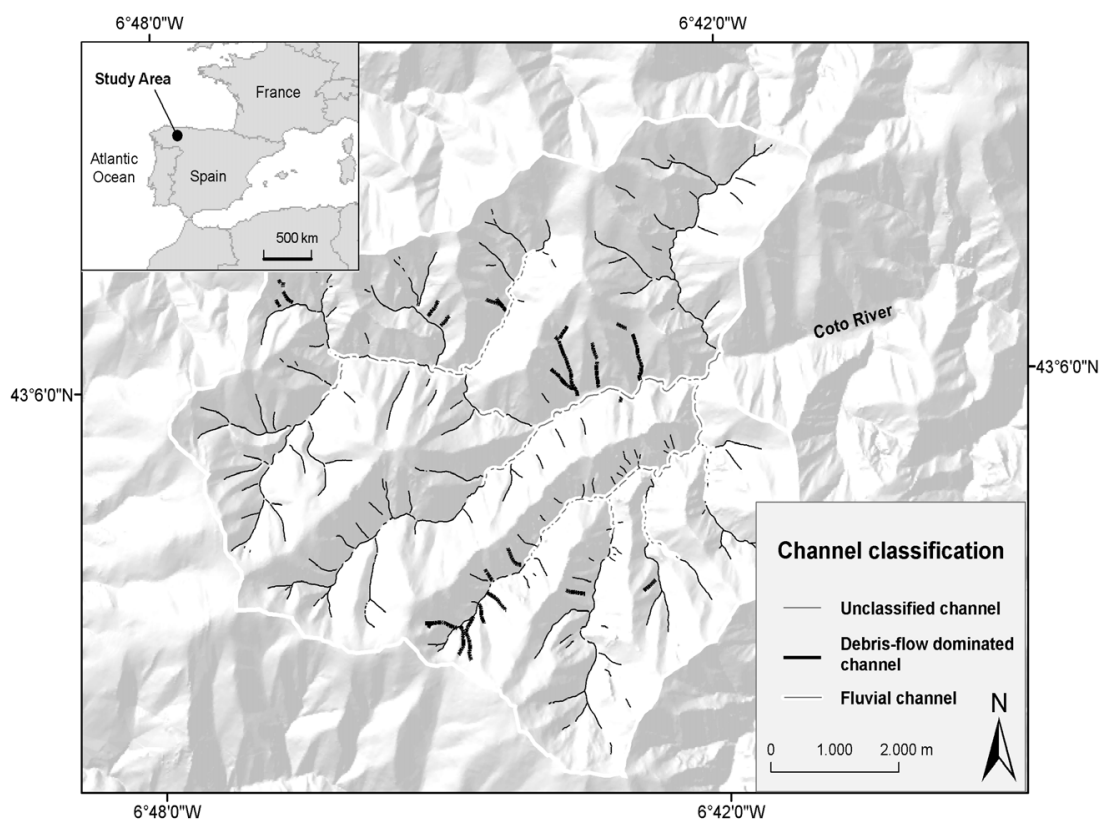

Figure 2: $\quad$ Situation of the study area (inset). The map shows the drainage network and the location of channel reaches that have been classified in the field according to the dominant geomorphic processes.

\section{Methodology}

Data collection for this study included air photo interpretation, GIS-based topographic analysis and field surveys at selected locations. Identification and delineation of headwater channels was performed through interpretation of aerial photographs and digital topography (at 1:15,000 and 1:5,000 scales, 
respectively). Channels were manually digitized, and prolonged upslope until channel heads, which were defined as points where topographic convergence is considerably reduced (Stock and Dietrich [9]), in transition to open slopes. Since this criterion was found to be ambiguous in some places, delineation of channels was also based on the recognition of channel-like features on aerial photographs, such as unweathered bedrock and lack of vegetation.

Area-slope data were extracted from topographic maps in a GIS environment, as described elsewhere (e.g. Stock and Dietrich [9]; Brardinoni and Hassan [11]). First, the drainage network was clipped into segments defined by consecutive contour lines, and slope was calculated for each one of them as the ratio between vertical drop $(5 \mathrm{~m})$ and segment length. Then, a $10 \mathrm{~m}$ digital elevation model was computed for the whole area; it included not only elevation data derived from topographic maps, but also the channel network, in order to capture more accurately its geometry. Finally, an accumulated flow model was derived from this DEM, and it was used to define the contributing area of each channel segment.

Field surveys included identification of debris flow evidences along headwater channels and additional observations, such as description of active geomorphic processes. Fieldwork focused on 18 channels with fan deposits at their confluences, since debris flow evidences are more likely to be preserved in them. On the other hand, recognition of fluvial activity was based on the presence of alluvial plains, terraces and relatively sorted channel beds. Additionally, channel slopes were measured at selected reaches by means of a hand-clinometer, in order to assess accuracy of data derived from topographic maps.

Classification of dominant transport processes was based on field evidences and available cartographic information, allowing for the definition of a lower morphometric threshold for colluvial channels. This threshold was extrapolated to the entire study area in order to estimate the importance and extent of debris flow dominated channels. Finally, this information was combined with a cartographic database of roads and settlements, in order to make a preliminary assessment of the potential risk associated to debris flows in the area.

\section{Results}

High-order channels (third to fifth order) usually run parallel to the dominant strike and are associated to clearly defined valleys, whereas low-order channels are developed on swales and often follow structural discontinuities, such as faults and joints. Slope-area data are summarized in fig. 3, showing a pattern described in other humid, mountain areas (e.g. Seidl and Dietrich [13]; Montgomery and Foufoula-Georgiou [15]; Stock and Dietrich [9]).

Alluvial plains and terraces, which characterise the fluvial domain (e.g. Stock and Dietrich [9]), are present along channels that follow the power-law distribution, whereas channels with evidences of debris flows clearly depart from this trend. The majority of fluvial reaches plot within the alluvial domain defined by Montgomery and Foufoula-Georgiou [15] (fig. 3), although there are some 
exceptions related to entrenched channels with anomalously high gradients. Similarly, debris flow dominated channels tend to be situated in the colluvial domain; reaches with unusual low gradients are generally on debris fans and surficial deposits.

The inflection between the colluvial and alluvial domains in the area-slope space is often described as a transitional zone where process domains overlap each other (Stock and Dietrich [9]; Brummer and Montgomery [14]; Benda et al. [16]). This transition zone is also observed in the study area as a broad inflection region defined by slopes between 0.1 and $0.7\left(5.7\right.$ to $\left.35.0^{\circ}\right)$, and contributing areas ranging from 1 to $10 \mathrm{~km}^{2}$.

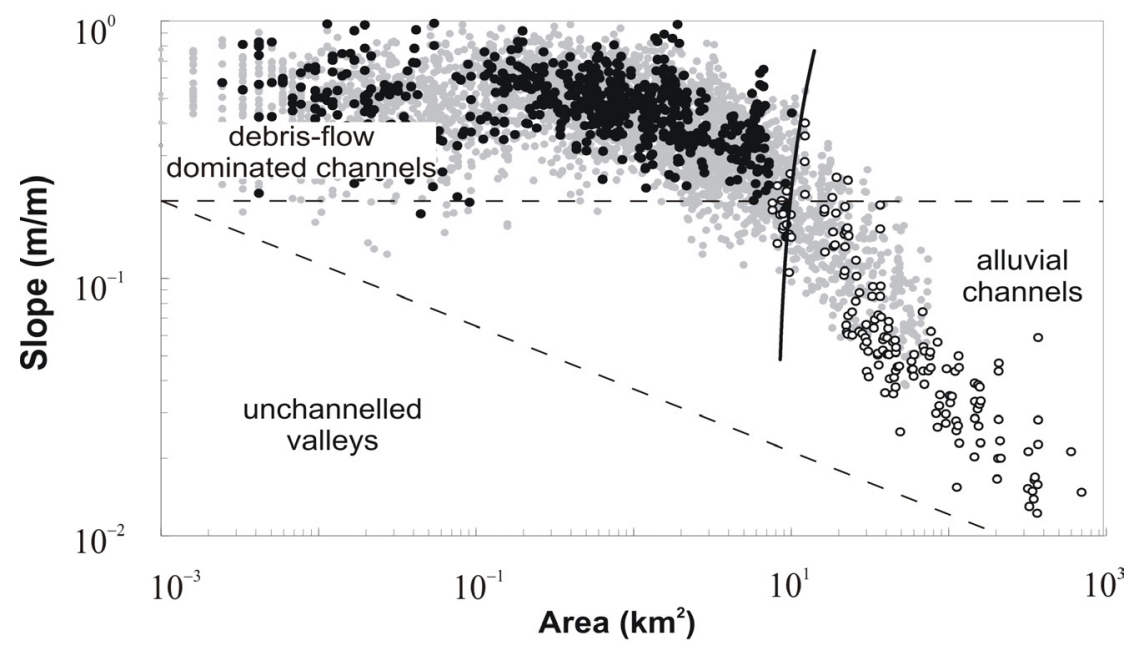

- Debris-flow dominated channels

Total dataset

- Fluvial channels

Threshold for debris-flow dominated channels

Figure 3: Area-slope plot of the study area. Open and solid circles represent channel reaches classified in the field as alluvial or colluvial channels, respectively, whereas grey points represent the entire dataset extracted from topography. The solid line indicates the lower threshold for colluvial channels deduced from the distribution of debris flow evidences in the area-slope space. Shaded lines represent the boundaries for process domains originally defined by Montgomery and Foufoula-Georgiou [15].

Previous morphometric research in headwaters concluded that channel slope data extracted from topographic maps may significantly depart from field data (e.g. Stock and Dietrich [9]; Brardinoni and Hassan [11]). Comparison between field and digitized slopes in the study area shows that data extracted from topographic maps differ from real values (fig. 4), although RMS Residuals Error (0.0329) is close to the error estimated for the hand clinometer. Deviation from 
field data is comparatively high for fluvial channels with large contributing basins, but it does not significantly modify the area-slope plot for channels with contributing areas smaller than $10 \mathrm{~km}^{2}$. Given that this research focuses on headwater channels, data derived from topography are considered to be accurate enough for the discrimination of process domains in the study area.

If the colluvial-alluvial boundary defined in fig. 3 is applied to the entire study area, it turns out that $64 \%$ of the drainage network lies within the debris flow dominated domain (fig. 5). Channels situated above this threshold are first and second-order channels with relatively high gradients. Therefore, they are morphologically very similar to those that had been previously defined in the field as colluvial channels. On the other hand, the area below this threshold contains alluvial channels with well developed valleys and moderate slopes.

Overlay of colluvial channels and infrastructures shows that 6 roads and one settlement are intersected by debris flow dominated channels (fig. 5). These sites are located along the boundaries of alluvial plains and valley slopes, which have been privileged areas for rural development in the area.

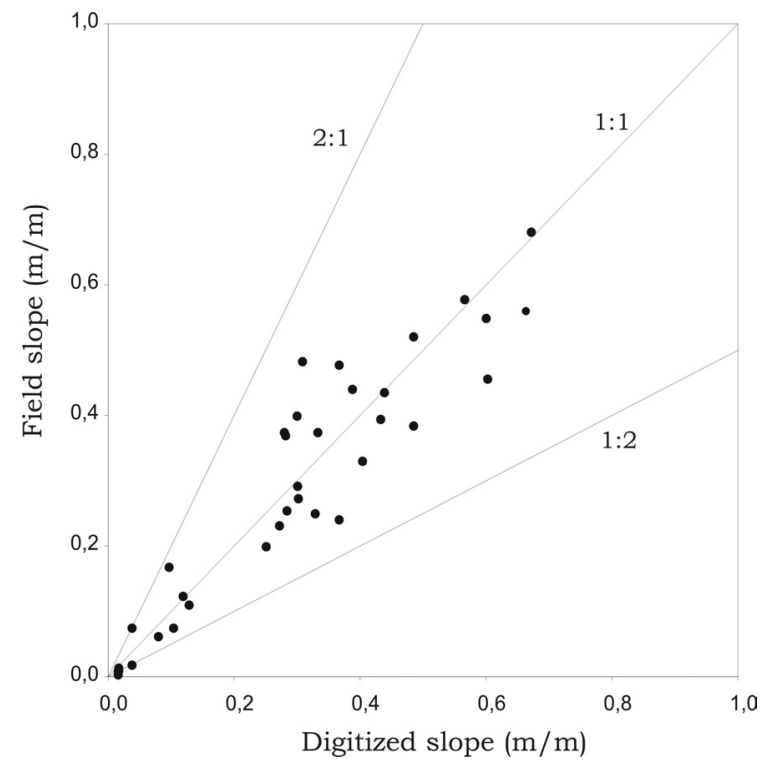

Figure 4: Comparison between field and digitized slopes in 35 reaches. Solid lines are defined by the ratios between field and digitized slopes.

\section{Discussion}

Distribution of area-slope data of headwater channels in the study area supports the hypothesis that geomorphic dynamics in headwater channels differ from fluvial channels, presumably due to debris flows being the dominant erosion and transport mechanism in upland channels. Given that colluvial and alluvial channels plot on fairly distinctive areas in the area-slope graph, it seems 
reasonable to use this distribution as a criterion for the identification of channels where debris flows are likely to cause significant damage. Montgomery and Foufoula-Georgiou [15] proposed a slope-constant threshold that separates the alluvial domain from the region where debris flow dominated channels plot in the area-slope space, (fig. 1). However, as discussed above, colluvial channels may have gradient values that are lower than those of the alluvial domain, whereas some alluvial channels plot close to the average gradient of debris flow dominated channels (fig. 3). Consequently, it seems that the identification of debris flow dominated channels in the study area should be based on both area and slope values. Adopting a conservative hazard criterion, the threshold for the identification of debris flow prone channels ought to contain all the channel reaches with evidences of debris flow activity (fig. 3).

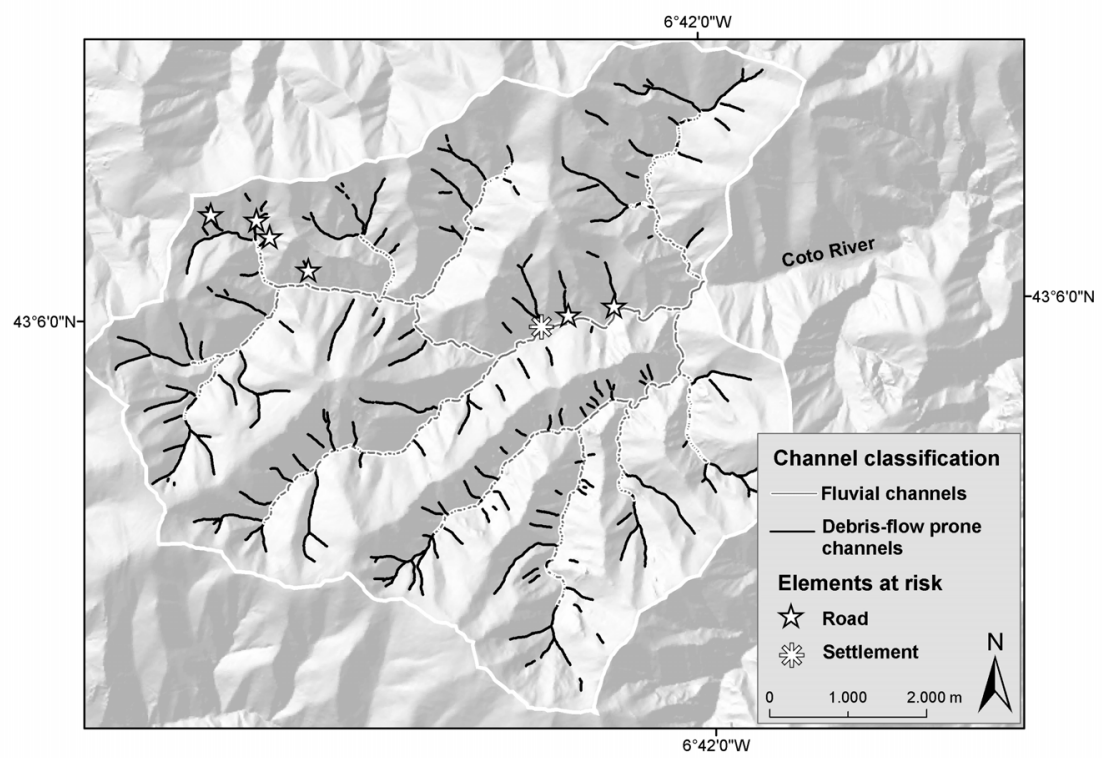

Figure 5: Identification of debris flow prone channels based on the morphometric threshold of fig. 3. Several roads and one settlement are intersected by these channels, thus being potentially threatened by debris flows.

Identification of colluvial channels based on a morphometric criterion reveals that $64 \%$ of the drainage network in the study area is dominated by debris flows. Although this figure is significantly lower than that obtained by Montgomery and Foufoula-Georgiou [15] in the Oregon Coast Range (approximately 90\%), it still encompasses a considerable fraction of the relief, implying that debris flows considerably contribute to the development of the regional landscape.

Given that nearly all the channels in the study area are dissected on colluvial deposits, sediment availability is usually high, and therefore debris flows are 
considered to be a significant threat along channels lying in the colluvial domain. According to this interpretation, roads and settlements intersected by colluvial channels are interpreted to be at risk, even though there are not reliable records of debris flow events at these locations. It is worth noting that only two of these sites are associated to debris fans; the rest of the channels affecting infrastructures do not build identifiable fans due to lack of space, thus being overlooked by conventional debris flow hazard assessments based on the recognition of debris fans.

\section{Conclusions}

This study has shown how the topographic signature of debris flow dominated channels may constitute a valid criterion for the recognition of debris flow hazard in headwater channels. Although the transition zone between debris flow and fluvially dominated channels in the area-slope space is rather imprecise, field data provide consistent criteria for the discrimination of headwater channels where gravity-driven flows are likely to occur. On the other hand, it becomes clear that geomorphic evidences of active processes must be incorporated into morphometric assessments of debris flow hazard, since there is a significant overlapping between colluvial and fluvial channels in the area-slope space. From a management perspective, debris flow hazard recognition based on the streampower model may be a useful tool for the identification of potentially hazardous sites, especially where fan deposits are absent.

\section{References}

[1] Hewitt, K., Risk and disaster in mountain lands. Mountains of the world: a global priority. Ed. The Parthenon Publishing Group, London, pp. 371408, 1997.

[2] Jakob, M., Debris-flow hazard analysis (Chapter 17). Debris-flow Hazards and Related Phenomena, ed. Praxis, Springer-Verlag: Berlin Heidelberg, pp. 411-443. 2005.

[3] VanDine, D.F., Debris flows and debris torrents in the Southern Canadian Cordillera. Canadian Geotechnical Journal, 22, pp. 44-68, 1985.

[4] de Scally, F.A. \& Owens, I.F., Morphometric controls and geomorphic responses on fans in the Southern Alps, New Zealand. Earth Surface Processes and Landforms, 29, pp. 311-322, 2004.

[5] Crosta, G.B. \& Frattini, P., Controls on modern alluvial fan processes in the Central Alps, Northern Italy. Earth Surface Processes and Landforms, 29, pp. 267-293, 2004.

[6] Wilford, D.J., Sakals, M.E., Innes, J.L., Sidle, R.C. \& Bergerud, W.A., Recognition of debris flow, debris flood and flood hazard through watershed morphometrics. Landslides, 1, pp. 61-66, 2002.

[7] Whipple. K.X. \& Tucker, G.E., Dynamics of the stream-power river incision model: Implications for height limits of mountain ranges, 
landscape response timescales, and research needs. Journal of Geophysical Research, 104(B8), pp. 17,661-17,674, 1999.

[8] Ijjasz-Vasquez, E.J. \& Bras, R.L., Scaling regimes of local slope versus contributing area in digital elevation models. Geomorphology, 12, pp. 299-311, 1995.

[9] Stock, J. \& Dietrich, W.E., Valley incision by debris flows: Evidence of a topographic signature. Water Resources Research, 39(4), 1089, 2003.

[10] Stock, J.D., Montgomery, D.R., Collins, B.D., Dietrich, W.E. \& Sklar, L., Field measurements of incision rates following bedrock exposure: Implications for process controls on the long profiles of valleys cut by rivers and debris flows. Geological Society of America Bulletin, 117(1112), pp. 179-194, 2005.

[11] Brardinoni, F. \& Hassan, M.A., Glacial erosion, evolution of river long profiles, and the organization of process domains in mountain drainage basins of coastal British Columbia. Journal of Geophysical Research, 111, F01013, 2006.

[12] Montgomery, D.R. \& Buffington, J.M., Channel-reach morphology in mountain drainage basins. Geological Society of America Bulletin, 109(5), pp. 596-611, 1997.

[13] Seidl, M. \& Dietrich, W.E., The problem of channel incision into bedrock. Functional Geomorphology, Catena Supplement, 23, ed. Catena-Verlag, Gremlingen, Germany, pp. 101-124, 1992.

[14] Brummer, C.J. \& Montgomery, D.R., Downstream coarsening in headwater channels. Water Resources Research, 39(10), 1294, 2003.

[15] Montgomery, D.R. \& Foufoula-Georgiou, E., Channel network source representation using digital elevation models. Water Resources Research, 29(12), pp. 3925-3934, 1993.

[16] Benda, L., Hassan, M.A., Church, M. \& May, C.L., Geomorphology of steepland headwaters: the transition from hillslopes to channels. Journal of the American Water Resources Association, 41(4), pp. 835-851, 2005. 